\title{
Efficacy Evaluation of Unique Skincare Product Containing Pseudo-Ceramide for Fine Wrinkles in Japanese Female Atopic Dermatitis Patients
}

\author{
Akihiko Takahashi*, Katsura Mori, Takahiro Nishizaka, Hisateru Tanabe \\ Kao Corporation, R\&D, Skincare Product Research, Tokyo, Japan \\ Email: takahashi.akihiko@kao.co.jp
}

Received 11 June 2014; revised 2 July 2014; accepted 3 August 2014

Copyright (C) 2014 by authors and Scientific Research Publishing Inc.

This work is licensed under the Creative Commons Attribution International License (CC BY). http://creativecommons.org/licenses/by/4.0/

(c) (7) Open Access

\begin{abstract}
Background/Objective: Dryness is considered to be an early developmental mechanism of wrinkles, and fine line formation is marked in atopic dermatitis (AD) accompanied by dry skin. To evaluate the efficacy of a skincare product with a moisturizing effect increased by lamellar formulation of pseudo-ceramide for fine lines and wrinkles, a use test was performed applying the product to non-lesional dry skin in patients with atopic dermatitis. Method: The test product was an essence containing pseudo-ceramide formulated in a lamellar structure. The study design was a nine-week single-center non-comparative study, and the evaluation items were the grade of wrinkles at the corners of the eyes judged by a dermatologist, replica analysis, and instrumental measurement (skin surface moisture and transepidermal water loss). Results: Nine-week continuous use of the test product significantly improved the score of wrinkles at the corners of the eyes judged by a dermatologist and wrinkle area ratio on replica analysis of the corners of the eyes and cheeks, compared with those at study initiation. With this improvement, the losses of skin surface moisture and transepidermal water were also significantly improved. Conclusion: It was clarified that the tested pseudo-ceramide-formulated skincare product not only improved the barrier function for atopic dermatitis, but also exhibited an effect on fine lines and wrinkles of dry skin.
\end{abstract}

\section{Keywords}

Pseudo-Ceramide, Fine Lines, Wrinkles, Atopic Dermatitis, Clinical Trial

${ }^{*}$ Corresponding author.

How to cite this paper: Takahashi, A., Mori, K., Nishizaka, T. and Tanabe, H. (2014) Efficacy Evaluation of Unique Skincare Product Containing Pseudo-Ceramide for Fine Wrinkles in Japanese Female Atopic Dermatitis Patients. Journal of Cosmetics, Dermatological Sciences and Applications, 4, 250-258. http://dx.doi.org/10.4236/jcdsa.2014.44034 


\section{Introduction}

Reduced barrier function and dryness of skin are observed in atopic dermatitis (AD), and a lack of intercellular lipids in the stratum corneum, particularly ceramide, is considered to be a cause of this, as it reduces skin surface moisture and increases transepidermal water loss in not only regions with eruptions but also non-lesional regions [1] [2]. Since skin elasticity reduction and wrinkle formation are likely to occur in dry skin, fine lines are readily formed due to reduced skin elasticity in $\mathrm{AD}$, in addition to dryness-induced rough skin surface and scales, and the skin appearance negatively influences the quality of life (QOL) of patients [3] [4]. However, no evaluation of the antiwrinkle efficacy of ceramide-formulated preparations for non-lesional dry skin of AD patients has been reported.

Improvement of dryness and barrier function by external use of ceramide and ceramide analogues in AD patients have been investigated, and a superior moisturizing effect and improvement of the barrier function have been clarified [5]. In addition, a technique to disperse pseudo-ceramide in a lamellar structure in water has recently been developed, for which a high and persistent moisturizing effect can be expected because the lamellar structure formed by pseudo-ceramide continuously retains water between the lamellar layers [6]. In this study, we performed a use test of a skincare product with a moisturizing effect increased by a lamellar formulation of pseudo-ceramide to confirm its efficacy for fine lines and wrinkles in AD patients.

\section{Materials and Methods}

\subsection{Test Product}

The test product was serum, in which pseudo-ceramide is formulated into a lamellar structure to increase the moisturizing effect (Table 1). The chemical structure of the pseudo-ceramide (cetyl PG hydroxyethyl palmitamide) is shown in Figure 1 [7].

\subsection{Study Design}

The study design was a single-center non-comparative study. After a one-week dry-out period, the test product was applied after face washing twice a day (morning and night) for nine weeks, instead of facial skincare products usually used, and the use of facial moisturizing products (emulsion, cream, and serum) other than the test product was prohibited.

\subsection{Evaluation}

Photography, instrumental measurement, and replica preparation were performed after acclimation to conditions of $22^{\circ} \mathrm{C}\left( \pm 2^{\circ} \mathrm{C}\right)$ temperature and $50 \%( \pm 5 \%)$ humidity for 20 minutes or longer. Skin surface moisture was measured in the cheek using Corneometer ${ }^{\circledR}$ MPA580 (Courage + Khazaka Electronic GmbH, Germany). Transepidermal water loss was measured in the cheek using Tewameter ${ }^{\circledR}$ TM210 (Courage + Khazaka Electronic GmbH, Germany). Photographs were taken using Nikon D3X (Nikon, Japan), and the grade of wrinkles at the corners of the eyes was evaluated based on photographs by a dermatologist. The criteria of the wrinkle level are shown in Table 2 [8].

Replicas were prepared from the corners of the eyes and cheek. Replica analysis was performed using ASA-03RXD (Asahi Bio-Rad, Japan), and the wrinkle area ratio was calculated by 2-dimensional parameter analysis [8].

\subsection{Statistical Analysis}

In statistical analysis of the grades of wrinkles evaluated by a dermatologist, the p-value was determined employing the Wilcoxon signed-rank test, followed by Bonferroni correction. For instrumental measurement and replica analysis, the p-value was determined employing the paired t-test, followed by Bonferroni correction. The significance level was set at $5 \%$ in both tests.

\subsection{Ethics}

An independent ethics committee was established, and the study was approved by this committee (Shinkoukai, Medical Corporation, Tokyo, Japan). The study was performed following the study protocol and ethical guide- 
Table 1. Ingredients of the test product.

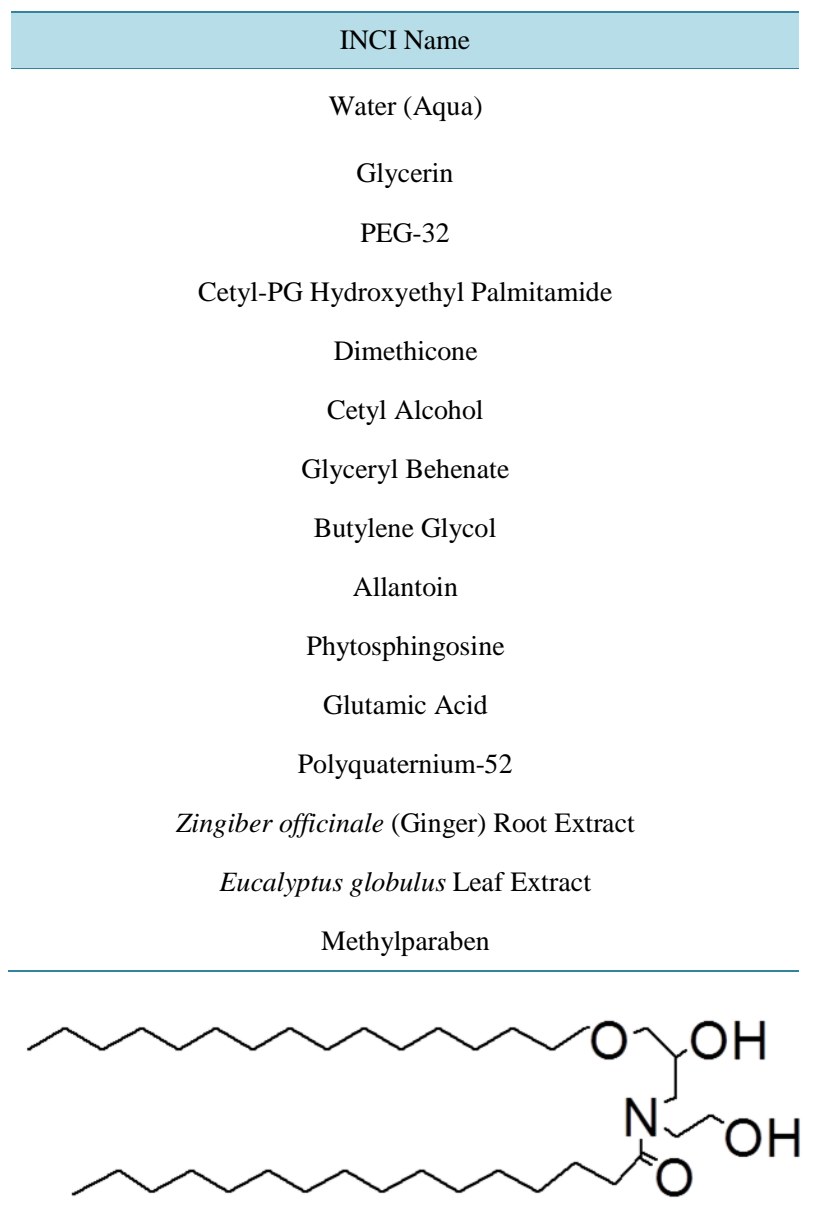

Figure 1. Chemical structure of pseudo-ceramide (Cetyl-PG Hydroxyethyl Palmitamide).

lines for clinical studies in conformity with ethical principles based on the Declaration of Helsinki.

\section{Results}

\subsection{Subjects}

Of Japanese female patients diagnosed by a dermatologist with very mild to mild AD based on the atopic dermatitis severity index, 22 patients aged 26 - 51 years (mean: 41 years old) with a specified wrinkle score $(1-3)$ of the corners of the eyes who gave informed consent participated in the study (Table 2). Table 3 shows the patients' background. Treatment was discontinued in one patient during the study period due to the development of erythema, scales, and lichenization at sites inconsistent with the region to which the test product had been applied, and this was assumed to be aggravation of AD. Accordingly, the final evaluation was made in 21 patients.

\subsection{Grade of Wrinkles at the Corners of the Eyes}

The grade of wrinkles was significantly improved compared with that at baseline at Weeks 4 and 9 after initiation of test product application (Table 4). Digital photographs of a markedly effective case are shown in Figure 2.

\subsection{Analysis of Replicas of Wrinkles at the Corners of the Eyes}

The wrinkle area ratio was significantly decreased from the baseline by the test product at Weeks 4 and 9 (Table 5). 
Table 2. Criteria of wrinkle score.

\begin{tabular}{cc}
\hline Grade & State of wrinkles \\
\hline 0 & Wrinkles are absent \\
1 & Only a few unclear shallow wrinkles are observed \\
2 & A few clear shallow wrinkles are observed \\
3 & Clear shallow wrinkles are observed \\
4 & A few slightly deep wrinkles are observed among clear shallow wrinkles \\
5 & Slightly deep wrinkles are observed \\
6 & Clear deep wrinkles are observed \\
7 & Markedly deep wrinkles are observed \\
\hline
\end{tabular}

\section{Table 3. Subjects’ background.}

\begin{tabular}{|c|c|c|c|c|c|c|c|}
\hline Number & Age & Gender & $\begin{array}{l}\text { Severity } \\
\text { of } \mathrm{AD}\end{array}$ & $\begin{array}{l}\text { Onset } \\
\text { of } \mathrm{AD}\end{array}$ & $\begin{array}{l}\text { Treatment history } \\
\text { for AD }\end{array}$ & $\begin{array}{l}\text { Treatment for } \\
\mathrm{AD} \text { (current) }\end{array}$ & Complications \\
\hline 001 & 29 & $\mathrm{~F}$ & Very Mild & 3 yo & Outpatient treatment (external application) & No treatment & \\
\hline 002 & 28 & $\mathrm{~F}$ & Mild & 0 yo & Outpatient treatment (external application) & No treatment & Pollinosis \\
\hline 003 & 41 & $\mathrm{~F}$ & Very Mild & 3 yo & Outpatient treatment (external application) & No treatment & Allergic coryza \\
\hline 004 & 43 & $\mathrm{~F}$ & Mild & 10 yo & Outpatient treatment (external application) & No treatment & Pollinosis \\
\hline 005 & 43 & $\mathrm{~F}$ & Very Mild & 39 yo & Outpatient treatment (external application) & No treatment & \\
\hline 006 & 40 & $\mathrm{~F}$ & Mild & 5 yo & Outpatient treatment (external application) & No treatment & $\begin{array}{l}\text { Pollinosis, } \\
\text { allergic coryza }\end{array}$ \\
\hline 007 & 43 & $\mathrm{~F}$ & Very Mild & 10 yo & Outpatient treatment (external application) & No treatment & \\
\hline 008 & 26 & $\mathrm{~F}$ & Very Mild & 3 yo & $\begin{array}{l}\text { Outpatient treatment (external and oral } \\
\text { application) }\end{array}$ & $\begin{array}{l}\text { Heparinoid lotion } \\
\text { (except face) }\end{array}$ & \\
\hline 009 & 39 & $\mathrm{~F}$ & Very Mild & 5 yo & Outpatient treatment (external application) & No treatment & \\
\hline 010 & 41 & $\mathrm{~F}$ & Very Mild & 5 yo & Outpatient treatment (external application) & $\begin{array}{l}\text { Tacrolims ointment } \\
\text { (except face) }\end{array}$ & $\begin{array}{l}\text { Pollinosis, contact } \\
\text { dermatitis (metal) }\end{array}$ \\
\hline 011 & 27 & $\mathrm{~F}$ & Very Mild & 5 yo & Outpatient treatment (external application) & No treatment & Pollinosis \\
\hline 012 & 38 & $\mathrm{~F}$ & Very Mild & 33 yo & $\begin{array}{l}\text { Outpatient treatment (external and } \\
\text { orally application) }\end{array}$ & No treatment & \\
\hline 013 & 48 & $\mathrm{~F}$ & Very Mild & 35 yo & Outpatient treatment (external application) & No treatment & Allergic coryza \\
\hline 014 & 34 & $\mathrm{~F}$ & Very Mild & 7 yo & Outpatient treatment (external application) & No treatment & Pollinosis, allergic coryza \\
\hline 015 & 51 & $\mathrm{~F}$ & Very Mild & 25 yo & No treatment & No treatment & \\
\hline 016 & 31 & $\mathrm{~F}$ & Very Mild & 8 yo & Outpatient treatment (external application) & No treatment & $\begin{array}{l}\text { Pollinosis, } \\
\text { allergic coryza }\end{array}$ \\
\hline 017 & 49 & $\mathrm{~F}$ & Very Mild & 22 yo & Outpatient treatment (external application) & No treatment & Pollinosis \\
\hline 018 & 41 & $\mathrm{~F}$ & Mild & 9 yo & Outpatient treatment (external application) & No treatment & \\
\hline 019 & 38 & $\mathrm{~F}$ & Very Mild & 25 yo & No treatment & No treatment & Pollinosis, allergic coryza \\
\hline 020 & 51 & $\mathrm{~F}$ & Very Mild & 30 yo & $\begin{array}{l}\text { Outpatient treatment (external and oral } \\
\text { application) }\end{array}$ & No treatment & Pollinosis \\
\hline 021 & 45 & $\mathrm{~F}$ & Mild & 7 yo & $\begin{array}{l}\text { Outpatient treatment (external and oral } \\
\text { application) }\end{array}$ & No treatment & \\
\hline 022 & 30 & $\mathrm{~F}$ & Very Mild & 6 yo & Treatment history for AD & No treatment & \\
\hline
\end{tabular}

Table 4. Changes in wrinkle score (crow’s feet).

\begin{tabular}{cccc}
\hline & Mean of wrinkle score & Standard error & Statistical analysis \\
Baseline & 2.51 & 0.12 & p $<0.05$ (vs. baseline) \\
Week 4 & 2.39 & 0.12 & p < 0.05 (vs. baseline) \\
Week 9 & 2.38 & 0.12 & \\
\hline
\end{tabular}

The test product improved wrinkles at the corners of the eyes, and the wrinkle scores at Weeks 4 and 9 were significantly lower than at baseline (Wilcoxon signed-lank test followed by Bonferroni correction). 
Table 5. Changes in wrinkle parameters on replica analysis (crow’s feet).

\begin{tabular}{cccc}
\hline & Mean of wrinkle area ratio & Standard error & Statistical analysis \\
\hline Baseline & 4.18 & 0.53 & 0.44 \\
Week 4 & 3.36 & 0.42 & p $<0.05$ (vs. baseline) \\
Week 9 & 3.16 & p $<0.05$ (vs. baseline) \\
\hline
\end{tabular}
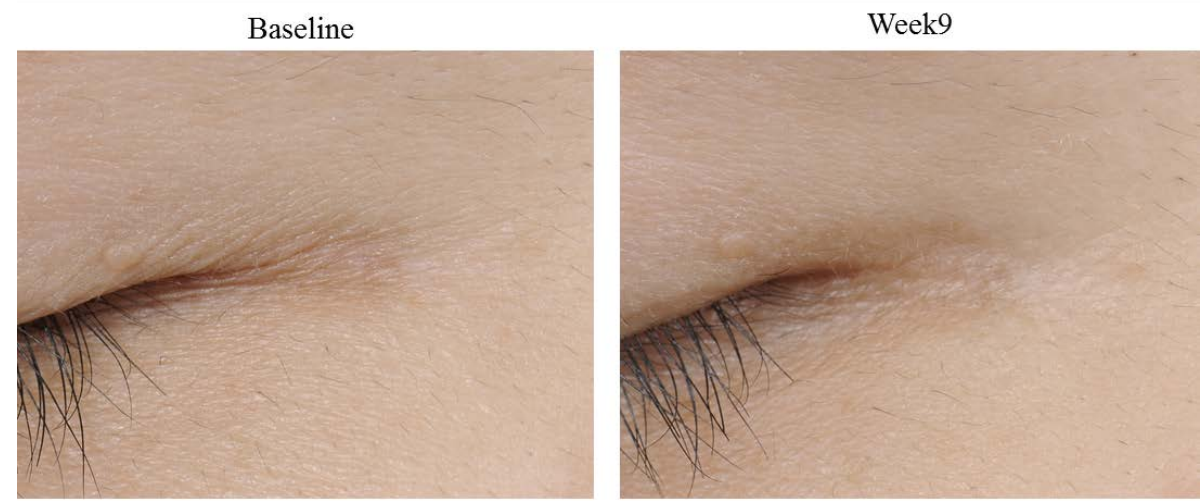

Figure 2. An improved case (crow's feet). Digital photographs of a case in which the 9-week use of the test product markedly improved wrinkles at the corners of the eyes.

Photographs of replicas of a markedly improved case are shown in Figure 3.

\subsection{Analysis of Replicas of Wrinkles in the Cheek}

The wrinkle area ratio was significantly decreased compared with that before test product application (Table 6). Photographs of replicas and digital photographs of the cheek of a markedly effective case are shown in Figure 4 and Figure 5, respectively.

\subsection{Skin Measurement}

Changes in the skin surface moisture from that on the first day of application were analyzed over time. The mean values at Weeks 4 and 9 were significantly higher than at baseline (Figure 6). Changes in transepidermal water loss from that on the first day of application were also analyzed over time. The mean value at Week 9 was significantly decreased from the baseline (Figure 7).

\section{Discussion}

It has been clarified that wrinkles, a symptom of aging, are formed due to age-related changes in skin elasticity and the degeneration of dermal collagen and elastin, and ultraviolet light and cigarette smoking are involved factors [9] [10]. In photoaging induced by chronic exposure to ultraviolet light, induction of matrix metalloproteinases (MMPs) is enhanced, and accompanying degradation of extracellular matrix, such as collagen Types I and III and elastin, promotes wrinkle formation [11].

In aging, reduction of skin thickness and changes in tissue structure result in fine wrinkles and sagging of skin tissue. In addition, deformity with changes in elasticity induced by reduction of the water content in the stratum corneum is involved in the formation and aggravation of fine wrinkles, for which moisturizing products are widely used to improve wrinkles and smooth the skin surface [12] [13]. In skin with reduced barrier function, the IL-1RA/IL- $1 \alpha$ level rises and increases IL-8 [14]. These inflammatory markers enhance MMP-1 and -9 production through the production of reactive oxygen species (ROS), and promote wrinkle formation induced by the degeneration of elastin and collagen [15].

Since dryness and reduced barrier function of the skin are among the causes of wrinkle formation, as described above, patients with skin diseases accompanied by dryness, such as AD, look older than their actual age, even though the severity is very mild with no skin eruption, which negatively influences the QOL of patients. 
Baseline

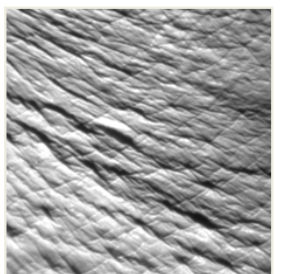

Figure 3. An improved case on replica photography (crow's feet). Replica photographs of a case in which the 9-week use of the test product markedly improved wrinkles at the corners of the eyes.
Baseline

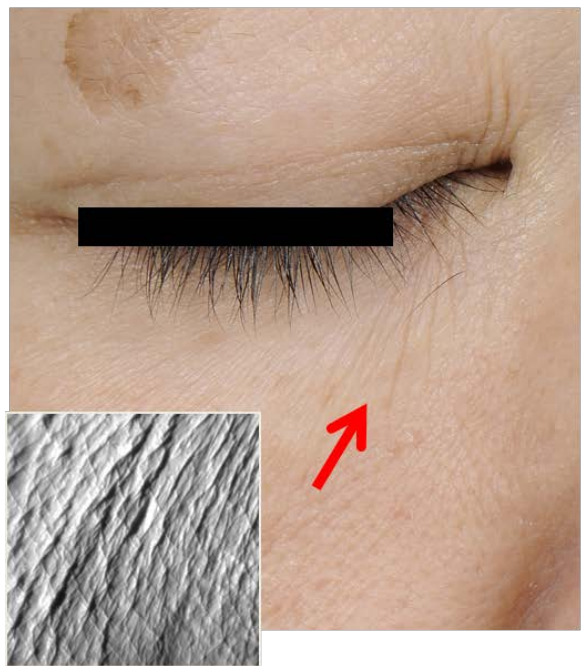

Week9

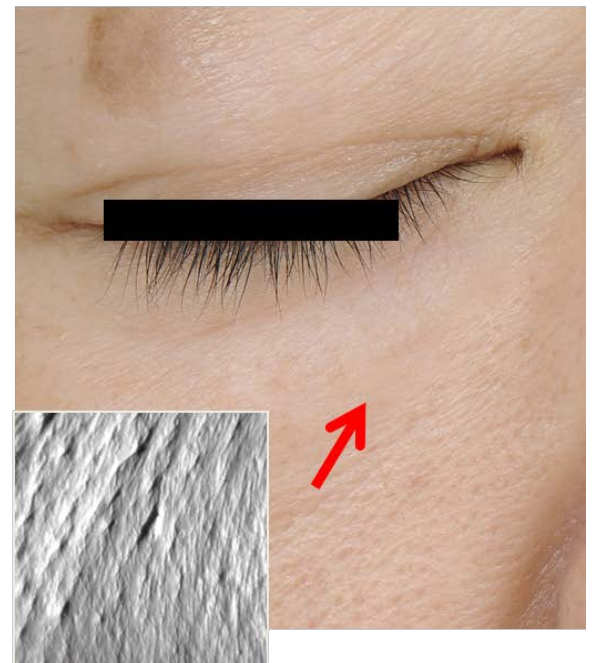

Figure 4. An improved case on replica photography (lower eyelid). Replica photographs of wrikles in the lower eyelid markedly improved by the 9-week use of the test product.

Baseline

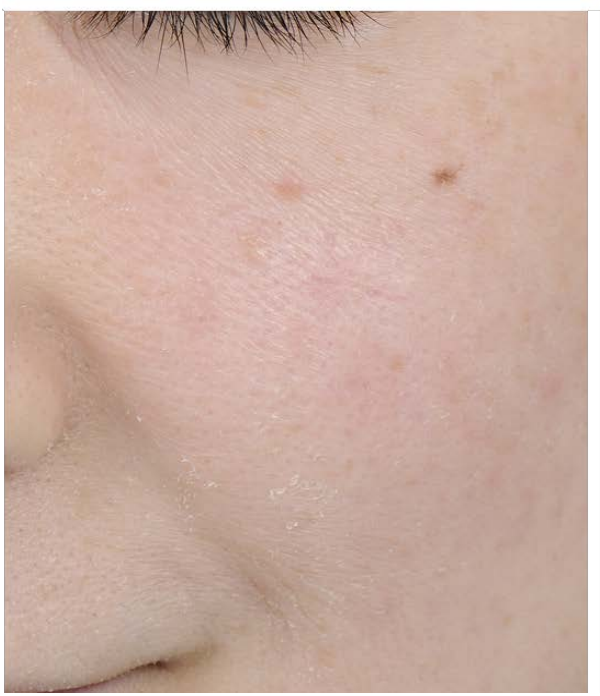

Week9

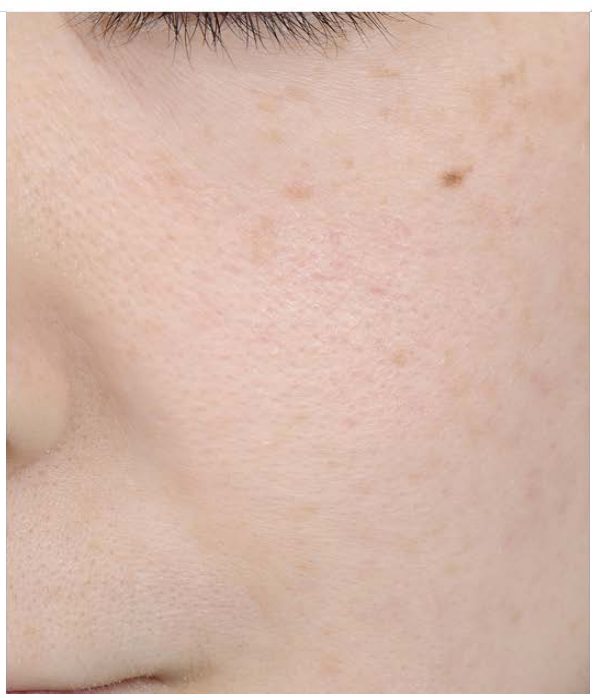

Figure 5. Photographs of an improved case. Digital photographs of a case markedly improved by the 9 -week use of the test product. Fine wrinkles in the lower eyelid and cheek, nasolabial folds, and scales were improved. 
Table 6. Changes in wrinkle parameters on replica analysis (lower eyelid).

\begin{tabular}{cccc}
\hline & Mean of wrinkle area ratio & Standard error & Statistical analysis \\
Baseline & 4.96 & 0.56 & 0.45 \\
Week 4 & 3.64 & 0.45 & p $<0.05$ (vs. baseline) \\
Week 9 & 4.01 & p $<0.05$ (vs. baseline) \\
\hline
\end{tabular}

The wrinkle area ratios in the lower eyelid at Weeks 4 and 9 were significantly lower than at baseline on replica analysis (paired t-test followed by Bonferroni correction).

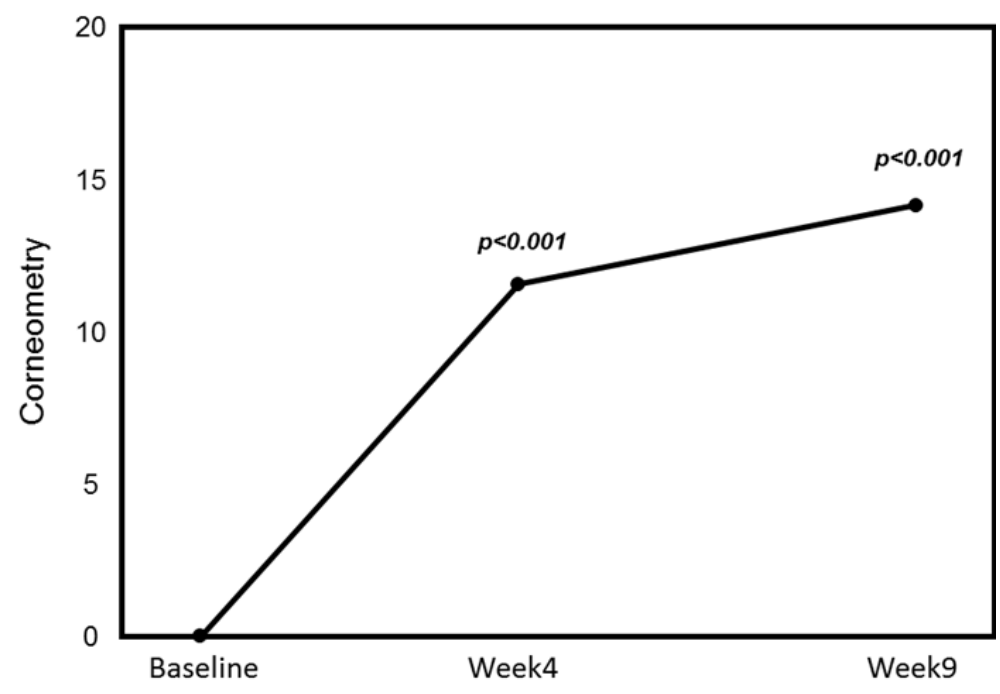

Figure 6. Changes in the cheek skin surface moisture. The cheek skin surface moisture was significantly increased at Weeks 4 and 9 compared with that at baseline $\left(^{*} \mathrm{p}<0.05,{ }^{* *} \mathrm{p}<0.01\right.$, paired t-test followed by Bonferroni correction).

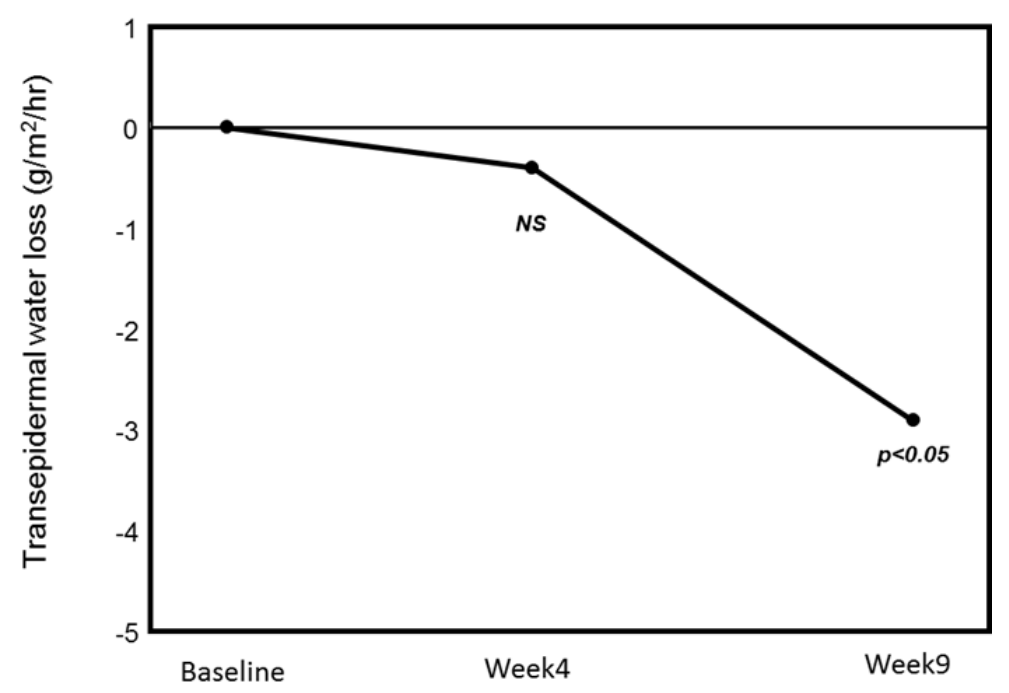

Figure 7. Changes in the cheek transepidermal water loss. The cheek transepidermal water loss was significantly decreased at Week 9 compared with that at baseline, improving the skin barrier function $\left({ }^{*} \mathrm{p}<0.05\right.$, paired t-test followed by Bonferroni correction).

The symptom of dryness in AD is considered to be due to insufficient intercellular lipids, particularly ceramide, in the stratum corneum, which reduces the skin barrier function and water retention ability [2]. The efficacy of 
external use of ceramide preparation for $\mathrm{AD}$ has been reported, and improvement of the skin barrier function has been shown, in addition to improvement of the skin appearance, particularly dryness and scales [5]. Kawakita et al. discussed that skin elasticity is reduced in $\mathrm{AD}$ because the skin barrier function and water retention ability are low [16]. Therefore, dry fine lines may be readily formed even in non-lesional regions in AD patients. However, clinical evaluation of ceramide-formulated skincare products for fine lines and wrinkles in AD has not previously been reported. Thus, we investigated the efficacy of a skincare product containing lamellar-formulated pseudo-ceramide for facial fine lines and wrinkles in patients with very mild to mild AD.

Nine-week application of the product significantly improved the score of wrinkles at the corners of the eyes judged by a dermatologist compared with that at baseline, suggesting that the test product is effective for fine wrinkles in AD patients with reduced barrier function. Various factors are considered to be involved in the improvement of wrinkles. The skin surface moisture was significantly increased and the transepidermal water loss was significantly decreased compared with those at study initiation, suggesting that inhibition of dryness of the stratum corneum through increasing skin surface moisture and inhibiting transepidermal water loss is a cause of improvement of wrinkles. Ceramide plays an important role in the maintenance of barrier function and water retention in the stratum corneum and improvement of the skin barrier function and surface moisture by pseudo-ceramide-formulated preparation has been demonstrated [17] [18]. The pseudo-ceramide formulated in the test product also improved the skin barrier function in AD-induced dry skin measured using the transepidermal water loss and skin surface moisture, which may have smoothed the skin surface. The pseudo-ceramide was formulated in a lamellar structure in the test product, similarly to intercellular lipids in the stratum corneum, and water retention between the layers facilitates persistent high moisture, which may have been effective for fine lines in dry skin. In addition, improved barrier function may have inhibited skin inflammation, which may have reduced MMP production and prevented degeneration of the extracellular matrix, inhibiting wrinkle formation [6]. Kawada et al. performed a use test of a niacinamide-formulated skin care product for fine wrinkles in healthy skin, and discussed its efficacy and association with the improvement of skin surface moisture and barrier function [19]. Erol et al. reported that positively charged nano-sized emulsion of ceramide lipid improved surface moisture and elasticity of the skin with atopic dermatitis [20]. An increase in the skin surface moisture reduced the wrinkle area ratio in replicas in our study, supporting their discussion.

Adverse events occurred in 2 patients. One was very mild stinging due to the test product. Its remission was achieved by temporarily stopping application of the test product, and application could later be restarted. The other was the development of erythema, lichenization, and scales at sites inconsistent with the region to which the test product had been applied, and these were in remission by 7 days oral treatment $\left(\right.$ Tauromin $^{\circledR}$ ). Since AD exhibits repeated remission and aggravation, this episode may have been due to periodic variation of AD.

Since this was a non-comparative study, the results were limited. However, fine lines were improved on both subjective evaluation (expert grading) and objective measurement (replica analysis), suggesting that the test product exhibits a wrinkle-improving effect. Improvement of fine lines and wrinkles or anti-aging by a ceramide preparation has not previously been reported. This study suggested its potential as a material for novel anti-aging care. Since this test product is very safe, it may be used as an anti-aging product applicable for sensitive skin. To clarify the anti-fine lines effect of ceramide, it is necessary to perform a double-blind study by comparison with a control group.

\section{Acknowledgements}

This study was supported financially by Kao Corporation (Tokyo, Japan). The authors would like to thank Dr. Numano, Dr. Taima, Ms. Kitajima, Mr. Takashima and Ms. Kanazawa for their assistance.

\section{References}

[1] Ishikawa, J., Narita, H., Kondo, N., Hotta, M., Takagi, Y., Masukawa, Y., Kitahara, T., Takema, Y., Koyano, S., Yamazaki, S. and Hatamochi, A. (2010) Change in Ceramide Profile of Atopic Dermatitis Patients. Journal of Investigative Dermatology, 130, 2511-2514. http://dx.doi.org/10.1038/jid.2010.161

[2] Loden, M., Olsson, H., Axell, T. and Linde, Y.M. (1992) Friction, Capacitance and Transepidermal Water Loss (TEWL) in Dry Atopic and Normal Skin. British Journal of Dermatology, 126, 137-141. http://dx.doi.org/10.1111/j.1365-2133.1992.tb07810.x

[3] Jae, W.C., Soon, H.K., Chang, H.H., Kyoung, C.P. and Sang, W.Y. (2013) The Influence of Skin Visco-Elasticity, 
Hydration Level and Aging on the Formation of Wrinkles: A Comprehensive and Objective Approach. Skin Research and Technology, 19, e349-e355. http://dx.doi.org/10.1111/j.1600-0846.2012.00650.x

[4] Juliane, H., Elisabrth, V., Florian, K. and Johannes, R. (2000) Biophysical Characteristics of Healthy Skin and Nonlesional Slin in Atopic Dermatitis: Short-Term Effects of Ultraviolet A and B Irradiation. Skin Pharmacology and Applied Skin Physiology, 13, 174-181. http://dx.doi.org/10.1159/000029923

[5] Chamlin, S.L., Kao, J., Freiden, I.J., Sheu, M.Y., Fowler, A.J., Fluhr, J.W., Williams, M.L. and Elias, P.M. (2002) Ceramide Dominant Barrier Repair Lipids Alleviate Childhood Atopic Dermatitis: Changes in Barrier Function Provide a Sensitive Indicator of Disease Activity. Journal of the American Academy of Dermatology, 47, 198-208. http://dx.doi.org/10.1067/mjd.2002.124617

[6] Iwai, H., Fukasawa, J. and Suzuki, T. (1998) A Liquid Crystal Application in Skin Care Cosmetics. International Journal of Cosmetic Science, 20, 87-102. http://dx.doi.org/10.1046/j.1467-2494.1998.171741.x

[7] Imokawa, G., Akasaki, S., Kawamata, A., Yano, S. and Takaishi, N. (1989) Water-Retaining Function in the Stratum Cornium and Its Recovery Properties by Synthetic Pseudo-Ceramides. Journal of the Society of Cosmetic Chemists, 40, 273-285.

[8] Task Force Committee for Evaluation of Anti-Aging Function (2007) Guideline for Evaluation of Anti-Wrinkle Products. J Japanese Cosmet Sci Soc, 31, 411-431.

[9] Leveque, J.L. (1999) EEMCO Guidance for the Assessment of Skin Topography. Journal of the European Academy of Dermatology and Venereology, 12, 103-114.

[10] Tsuji, N., Moriwaki, S., Suzuki, Y., Takema, Y. and Imokawa, G. (2001) The Role of Elastases Secreted by Fibroblasts in Wrinkle Formation: Implication through Selective Inhibition of Elastase Activity. Photochemistry and Photobiology, 74, 283-290. http://dx.doi.org/10.1562/0031-8655(2001)074<0283:TROESB>2.0.CO;2

[11] Yin, L., Morita, A. and Tsuji, T. (2001) Skin Ageing Induced by Ultraviolet Exposure and Tabacco Smoking: Evidence from Epidermiological and Molecular Studies. Photodermatology, Photoimmunology and Photomedicine, 17, 178-183. http://dx.doi.org/10.1034/j.1600-0781.2001.170407.x

[12] Krutmann, J. and Glichrest, B.A. (2006) Photoaging of Skin. In: Glichrest, B.A. and Krutmann, J., Ed., Skin Aging, Springer, Heiderberg, 33-43.

[13] Jae, W.C., Soon, H.K., Chang, H.H., Kyoung, C.P. and Sang, W.Y. (2013) The Influence of Skin Visco-Elasticity, Hydration Level and Aging on the Formation of Wrinkles: A Comprehensive and Objective Approach. Skin Research and Technology, 19, e349-e355. http://dx.doi.org/10.1111/j.1600-0846.2012.00650.x

[14] Katherine, N. and Ellen, M. (2012) Moisturizers: Reality and the Skin Benefits. Dermatology and Therapy, 25, 229-233. http://dx.doi.org/10.1111/j.1529-8019.2012.01504.x

[15] Jongh, C.M., Verberk, M.M., Withagen, C.E.T., Jacobs, J.J.L., Rustemeyer, T. and Kezic, S. (2006) Stratum Cornium Cytokines and Skin Irritation Response to Sodium Lauryl Sulfate. Contact Dermatitis, 54, 325-333. http://dx.doi.org/10.1111/j.0105-1873.2006.00848.x

[16] Shin, M.H., Rhie, G., Kim, Y.K., Park, C.H., Cho, K.H., Kim, K.H., Eun, H.C. and Chung, J.H. (2005) $\mathrm{H}_{2} \mathrm{O}_{2}$ Accumulating by Catalase Reduction Changes MAP Kinase Signaling in Aged Human Skin in Vivo. Journal of Investigative Dermatology, 125, 221-229.

[17] Kawakita, T., Takano, Y., Asano-Kato, N., Tanaka, M., Dogru, M., Goto, E., Tsubota, K., Takahashi, S., Fukagawa, K. and Fujishima, H. (2004) Quantitative Evaluation of Eyelid Elasticity Using the Cutometer SEM575 and Its Clinical Application in Assessing the Efficacy of Tacrolimus Ointment Treatment in eyelid Atopic Dermatitis. Cornea, 23, 468-471. http://dx.doi.org/10.1097/01.ico.0000116521.57227.4c

[18] Elias, P.M. (1983) Epidermal Lipids, Barrier Function and Desquamation. Journal of Investigative Dermatology, 80, 44s-49s. http://dx.doi.org/10.1038/jid.1983.12

[19] Leon, K., Firas, H. and Joseph, B. (2013) Atopic Dermatitis, and the Role of Ceramide-Dominant, Physiologic Lipid-Based Barrier Repair Emulsion. Journal of Drugs in Dermatology, 12, 1024-1027.

[20] Kawada, A., Konishi, N., Oiso, N., Kawara, S. and Date, A. (2008) Evaluation of Anti-Wrinkle Effects of a Novel Cosmetic Containing Niacinamide. The Journal of Dermatology, 35, 637-642. http://dx.doi.org/10.1111/j.1346-8138.2008.00537.x

[21] Erol, Y. and Hans-Hubert, B. (2006) Effect of Lipid-Containing, Positively Charged Nanoemulsions on Skin Hydration, Elasticity and Erythema-An in Vivo Study. International Journal of Pharmaceutics, 307, 232-238. http://dx.doi.org/10.1016/j.ijpharm.2005.10.002 
Scientific Research Publishing (SCIRP) is one of the largest Open Access journal publishers. It is currently publishing more than 200 open access, online, peer-reviewed journals covering a wide range of academic disciplines. SCIRP serves the worldwide academic communities and contributes to the progress and application of science with its publication.

Other selected journals from SCIRP are listed as below. Submit your manuscript to us via either submit@scirp.org or Online Submission Portal.
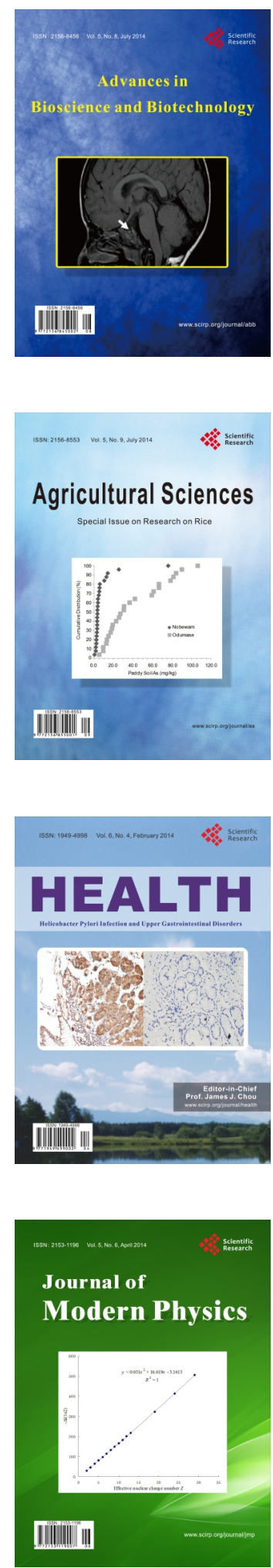
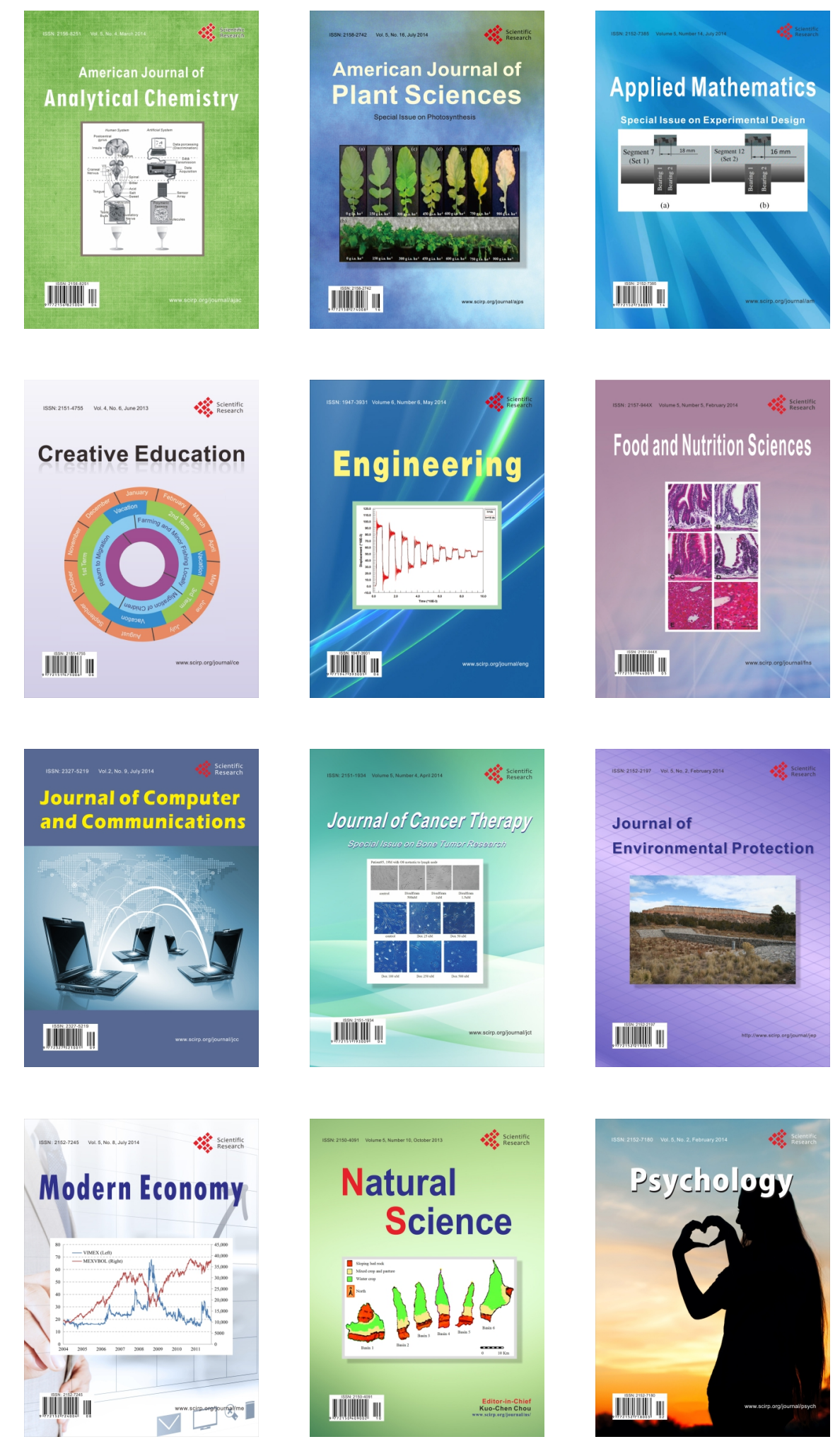